\title{
Analisis Pengaruh Variasi Sudut Blasting dengan Coating Campuran Epoxy dan Aluminium Serbuk terhadap Kekuatan Adhesi, Prediksi Laju Korosi, dan Morfologi pada Plat Baja ASTM A36
}

\author{
Muhammad Sulton Ali, Herman Praktikno, Wimala L. Dhanistha \\ Departemen Teknik Kelautan, Fakultas Teknologi Kelautan, \\ Institut Teknologi Sepuluh Nopember (ITS) \\ e-mail: muhammadsultonali@gmail.com; hermanp@oe.its.ac.id
}

\begin{abstract}
Abstrak-Permasalahan korosi merupakan masalah utama penyebab terjadinya kegagalan pada material terutama pada bangunan laut, dimana biasanya ditempatkan pada kondisi atau lingkungan yang korosif. Salah satu langkah preventif yang digunakan untuk memperlambat korosi pada suatu material adalah dengan metode pelapisan atau coating. Pada penelitian ini menggunakan material ASTM A36. Baja ini dijadikan bahan uji karena baja ASTM 36 baja yang sering dijadikan material pada bangunan laut. Metode yang digunakan untuk penelitian adalah dengan memvariasikan sudut blasting dengan coating yang digunakan adalah campuran epoxy dan aluminium serbuk. Variasi campuran coating nya yaitu $10 \%$ aluminium serbuk ditambah epoxy, $20 \%$ aluminium ditambah epoxy dan $30 \%$ aluminium ditambah epoxy. Yang pertamana baja ASTM A36 dipotong menjadi 18 spesimen kemudian coating dilapiskan ke tiap-tiap spesimen dengan campuran aluminium yang sudah divariasikan. Setelah itu ke enam spesimen tersebut diuji kekuatan adhesi dan diuji yang kedua untuk mendapatkan prediksi laju korosi. Pada pengujian Pull-Off nilai terbaik dimiliki oleh spesimen dengan variasi penambahan aluminium serbuk $10 \%$ dan variasi sudut blasting $90^{\circ}$ dengan nilai sebesar $14.9367 \mathrm{MPa}$. Sedangkan pada pengujian sel tiga elektroda menunjukkan bahwa ketahanan korosi terbaik didapat pada spesimen dengan penambahan aluminium $30 \%$ dan variasi sudut blasting $90^{\circ}$ dengan nilai sebesar 0,00008567 mmpy. Untuk pengujian SEM menunjukkan bahwa terlihat pigmen aluminium yang berbentuk platey atau lamellar dan terlihat persebaran aluminium serbuk dipermukaan sampel yang merata.
\end{abstract}

Kata kunci-Baja ASTM A36, Coating, Epoxy, Aluminium, Adhesi, Korosi.

\section{PENDAHULUAN}

$I^{\mathrm{N}}$ NDUSTRI maritim di Indonesia tumbuh pesat akhir-akhir ini. Produksi pembuatan kapal juga seiring tumbuh pesat pula. Perkembangan industri maritim Indonesia harus diimbangi dengan peningkatan mutu alat transportasi laut yaitu kapal. Ditambah adanya kebijakan perintah mengenai Tol Laut mendorong perusahaan industri kapal memproduksi kapal dalam jumlah yang besar. Disamping itu bahan dalam pembuatan kapal dituntut mampu tahan dalam kondisi operasional dalam jangka panjang. Kapal sendiri terbuat dari jenis baja. Baja telah lama digunakan secara luas didalam industri kapal sebagai komponen plat utama didalam badan maupun lambung kapal. Di dalam lingkungan industri perkapalan, penggunaan material baja menempati urutan pertama sebagai komponen bangunan kapal, sistem persenjataan, mesin utama maupun mesin bantu kapal. Disatu sisi material baja didalam kapal sangat rentan terhadap serangan korosi yang dapat menurunkan kualitas material kapal [1].

Salah satu dari sifat suatu material adalah tahan terhadap korosi. Pada korosi itu secara alamiah tidak dapat dicegah tapi hanya dapat dihambat. Serangan korosi umumnya berbeda-beda dan dalam kasus tertentu sangat berbahaya. Korosi itu sendiri merupakan masalah yang sangat serius dalam dunia material, karena dapat mengakibatkan kerugiankerugian yang besar, antara lain dapat menimbulkan kebocoran, meledaknya suatu pipa atau bejana bertekanan dan mungkin juga akan membuat pencemaran pada kualitas suatu produk. Korosi menghabiskan material-material pada konstruksi termasuk material logam, sehingga mengurangi kekuatan dan umur konstruksi. Korosi juga merugikan dunia industri secara ekonomis yaitu perlunya alokasi dana untuk inspeksi dan perawatan secara berkala pada konstruksi.

Dalam ini ada banyak metode-metode pengendalian korosi yang pernah dilakukan diantaranya, dengan metode pelindungan secara aktif (Dengan metode Cathodic Protection). Cathodic Protection adalah teknik yang digunakan untuk mengendalikan korosi pada permukaan logam dengan menjadikan permukaan logam tersebut sebagai katode dari sel volta.

Pengendalian korosi juga dapat menggunakan metode Coating. Metode yang digunakan adalah proteksi penghalang (barrier protection). Biasanya metode ini diaplikasikan dalam bentuk lapisan organic (organic coating). Metode ini merupakan metode yang paling banyak digunakan dikarenakan metode ini mudah untuk dilakukan [2]. Selain itu usia pakai dari lapisan organik juga cukup panjang dimana biaya yang dibutuhkan menjadi lebih sedikit dibandingkan dengan metode lainnya. Dalam hal ini yang digunakan metode pengendalian korosi yaitu dengan coating. Coating sendiri merupakan proses untuk melapisi suatu bahan dasar (substrate) yang bertujuan untuk melindungi material dari korosi dan memberikan perlindungan pada material. Cat yang dipakai pada coating bermacam-macam ada cat primer, cat intermediet, dan top up. Pada analisis ini menggunakan cat primer epoxy dengan pencampuran aluminium (Al) serbuk. Pencampuran antara keduanya diambil dengan variasi 
presentse aluminium itu sendiri. Diambil variasi prosentase aluminium yaitu, 10\%, 20\%, dan 30\%.

Dalam penelitian ini, yang akan dilakukan adalah menganalisis pengaruh variasi sudut penyemprotan blasting dan variasi pencampuran alumunium (Al) serbuk dengan cat primer epoxy dengan metode sand blasting yang diharapkan untuk mendapatkan hasil nilai kekuatan adhesi, morfologi, dan prediksi laju korosi pada baja karbon rendah ASTM A36 dilingkungan korosif $\mathrm{NaCl}$ 3,5\%.

\section{DASAR TEORI}

\section{A. Pengertian Baja}

Besi murni (ferit) tentulah tidak mengandung karbon. Besi ini relatif lunak dan liat serta mampu tempa, tetapi tidak kuat. Hampir semua besi murni mempunyai suatu kekuatan tarik batas sekitar 40.000 psi. Penambahan karbon ke dalam besi murni dalam jumlah yang berkisar dari 0,05 sampai 1,7 persen, menghasilkan apa yang dikenal sebagai baja.

\section{1) Baja karbon rendah}

Mengandung karbon antara 0,05 hingga 0,30 wt\% C. Memiliki kekuatan luluh (yield strength) $275 \mathrm{MPa}$ (40.000 psi), kekuatan tarik (tensile strength) antara 415 dan $550 \mathrm{MPa}$ (60.000 dan 80.000 psi), dan keuletan (ductility) dari 25\% EL. Relatif lunak dan lemah tetapi memiliki ketangguhan dan keuletan yang luar biasa. Di samping itu, baja karbon rendah memiliki sifat mudah ditempa, mudah di mesin, dan mudah di las.

\section{2) Baja karbon menengah}

Memiliki konsentrasi karbon berkisar antara 0,30 hingga $0,60 \mathrm{wt} \% \mathrm{C}$. Memiliki tingkat kekuatan yang lebih tinggi dibandingkan dengan baja karbon rendah. Mempunyai sifat yang sulit dibengkokkan, di las, dan dipotong.

\section{3) Baja karbon tinggi}

Biasanya mengandung karbon sebesar 0,60 hingga 1,4 wt\% C. Merupakan baja karbon yang paling sulit untuk dibentuk, ditempa, di las, dan dipotong tetapi memiliki tingkat keuletan paling tinggi. Memiliki sifat yang sangat keras dan tahan aus. Baja karbon tinggi ini biasa digunakan untuk mesin pemotong, pisau, pisau gergaji besi, per (spring), dan kawat baja berkekuatan tinggi.

Dari ketiga Baja dengan kandungan karbon masing masing, Baja ASTM A36 masuk dalam kategori baja dengan tingkat karbon rendah yang memiliki keuletan tinggi, mudah dimachining dan baja yang paling sering digunakan dalam industri maritim termasuk pembuatan kapal. Dikatakan rendah karena mengandung karbon antara $0.05 \%-0.3 \%$. Menurut ASTM komposisi dan kekuatan baja ASTM A36 adalah sebagai berikut:

Tabel 1.

Komposisi baja A36

\begin{tabular}{cc}
\hline \hline Elements & Compositions (\%) \\
\hline Carbon & $0.260 \%$ \\
Copper & $0.20 \%$ \\
Iron & $99.0 \%$ \\
Manganese & $0.75 \%$ \\
Phosphorous & $0.040 \%$ \\
Sulfur & $0.050 \%$ \\
\hline \hline
\end{tabular}

Tabel 2

Kekuatan baja A36

\begin{tabular}{|c|c|}
\hline Properties & Amount \\
\hline Tensile Stress (Mpa) & $400-500$ \\
\hline Yield Strength (Mpa) & 250 \\
\hline Elongation at break (\%) & $23 \%$ \\
\hline
\end{tabular}

\section{B. Korosi}

Korosi dapat didefinisikan sebagai kerusakan dari material karena reaksi dengan lingkungan disekitarnya. Beberapa menyebutkan bahwa definisi ini hanya dibatasi untuk logam, tetapi sering corrosion engineer harus mempertimbangkan baik logam maupun non-logam untuk solusi penyelesaiaan suatu masalah.

Mekanisme terjadinya korosi yang terjadi pada logam disebabkan adanya reaksi yang melibatkan dua reaksi setengah sel, yaitu reaksi oksidasi pada anoda dan reaksi reduksi pada katoda dan anoda yang terjadi dalam suatu proses korosi adalah sebagai berikut.

$$
\begin{aligned}
& \text { 1. Anoda } \\
& \text { 2. Katoda } \\
& \text { 3. Elektrolit } \\
& \text { 4. Kontak Melatik (Metallic Pathway) } \\
& \text { Mekanisme reaksi korosi dapat dilihat sebagai berikut: } \\
& \mathrm{Fe}(\mathrm{s})+\mathrm{H} 2 \mathrm{O}(\mathrm{l})+1 / 2 \mathrm{O} 2(\mathrm{~g}) \rightarrow \mathrm{Fe}(\mathrm{OH}) 2(\mathrm{~s}) \\
& 4 \mathrm{Fe}(\mathrm{OH}) 2(\mathrm{~s})+\mathrm{O} 2(\mathrm{~g})+2 \mathrm{H} 2 \mathrm{O}(\mathrm{l}) \rightarrow 4 \mathrm{Fe}(\mathrm{OH}) 3(\mathrm{~s}) \\
& 2 \mathrm{Fe}(\mathrm{OH}) 3 \rightarrow \mathrm{Fe} 2 \mathrm{O} 3+3 \mathrm{H} 2 \mathrm{O}
\end{aligned}
$$

Baja memiliki sebuah lapisan proteksi yang lemah pada permukaannya, dengan adanya uap air dan oksigen korosi terjadi. Korosi adalah reaksi elektrokimia, pada dasarnya proses yang terjadi sama dengan proses pada sel elektrolit sederhana, dimana bahan utamanya adalah sebuah sel dengan dua elektroda yaitu anoda dan katoda digabungkan oleh konduktor eksternal dan tercelup didalam sebuah elektrolit, dapat dilihat seperti pada Gambar 1.

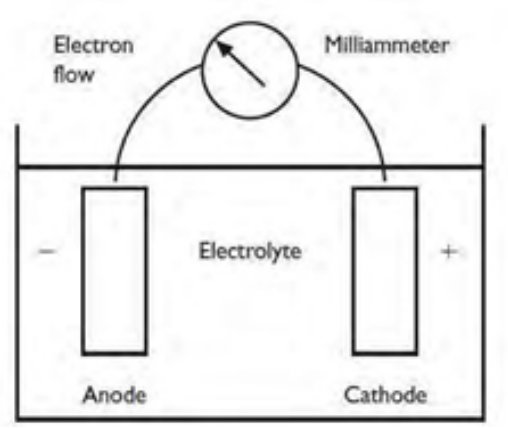

Gambar 1. Sel Elektrolit Sederhana.

\section{Laju Korosi}

Laju korosi adalah suatu parameter yang menunjukkan tingkat penetrasi korosi yang terjadi pada suatu material. Laju korosi adalah parameter yang sering digunakan pada pengujian korosi dikarenakan sangat berpengaruh terhadap nilai ekonomis dan teknis material. Terdapat dua metode untuk menghitung laju korosi, yakni dengan metode kehilangan berat (weight loss) dan dengan metode elektrolisis.

Pada penelitian ini menggunakan metode elektrolisis, laju korosi dihitung dengan bantuan sel elektrokimia yang dalam penelitian ini menggunakan jenis sel tiga elektroda. Sel elektrokimia ini akan memberikan potensial pada material uji sehingga akan terjadi korosi akibat adanya reaksi katodik dan anodik. Kelebihan dari metode ini adalah tidak dibutuhkannya waktu yang lama untuk mengetahui laju korosi dikarenakan nilai tersebut akan langsung diketahui pada saat pengujian dilakukan. Nilai laju korosi dapat dihitung dengan menggunakan persamaan Faraday sebagai berikut:

$$
C R(m p y)=K \frac{a i}{n D}
$$


Dengan,

$\mathrm{CR}=$ Laju korosi (mpy)

$\mathrm{K}=$ Konstanta faktor $(\mathrm{mpy}=0.129 ; \mu \mathrm{m} / \mathrm{yr}=3.27 ; \mathrm{mm} / \mathrm{yr}$ $=0.00327$ )

$\mathrm{a}=$ Berat atom logam yang terkorosi (gram)

$\mathrm{i} \quad=$ Kerapatan arus $\left(\mu \mathrm{A} / \mathrm{cm}^{2}\right)$

$\mathrm{D}=$ Densitas logam terkorosi $\left(\mathrm{gram} / \mathrm{cm}^{3}\right)$ $\mathrm{n} \quad=$ Jumlah elektron valensi logam terkorosi

Semakin kecil nilai laju korosi suatu material, sifat ketahanan korosinya semakin baik. Ketahanan korosi material dapat diklasifikasikan berdasarkan nilai laju korosinya sebagai berikut:

Tabel 3

Kriteria ketahanan material berdasarkan laju korosi

\begin{tabular}{llllll}
\hline \hline Relative Corrosion Resistance & mpy & Mm/year & $\boldsymbol{\mu m} / \boldsymbol{y e a r}$ & $\mathbf{n m} /$ year & $\mathbf{p m / s e c}$ \\
\hline Outsanding & $<1$ & $<0.02$ & $<25$ & $<2$ & $<1$ \\
Excellent & $1-5$ & $0.02-0.1$ & $25-100$ & $2-10$ & $1-5$ \\
Good & $5-20$ & $0.1-0.5$ & $100-500$ & $10-50$ & $5-20$ \\
Fair & $20-50$ & $0.5-1$ & $500-1000$ & $50-100$ & $20-50$ \\
Poor & $50-200$ & $1-5$ & $1000-5000$ & $150-500$ & $50-200$ \\
Unacceptable & $>200$ & $>5$ & $>5000$ & $>500$ & $>200$ \\
\hline \hline
\end{tabular}

\section{Epoxy}

Resin epoxy atau secara umum dikenal dengan bahan epoxy adalah salah satu jenis polimer yang berasal dari kelompok thermoset, yang dibentuk melalui proses polimerisasi kondensasi, bahan plastik yang tidak dapat dilunakkan kembali atau dibentuk kembali kekeadaan sebelum pengeringan.

Resin epoxy mempunyai sifat-sifat: berstruktur amorf, tidak bisa meleleh, tidak bisa didaur ulang, atom-atomnya berikatan kuat sekali. Keunggulan yang dimiliki resin epoxy ini adalah ketahanan terhadap panas dan kelembaban, sifat mekanik yang baik, tahan terhadap bahan-bahan kimia, sifat insulator, sifat perekatnya yang baik terhadap berbagai bahan, dan resin ini mudah dalam modifikasi dan pembuatannya.

\section{E. Epoxy sebagai Material Coating}

Epoxy adalah jenis polimer yang bisa digunakan untuk pelapisan dalam bentuk liquid maupun powder. Epoxy memiliki kepadatan dan daya adhesi yang tinggi sehingga memengaruhi ketahanan korosi pada baja yang dilapisinya.

Epoxy adalah coating yang paling sering digunakan karena banyak kelebihannya. Pertama, mudah dalam proses coating karena memiliki sifat surface tolerant (tidak membutuhkan kekasaran atau tingkat kebersihan yang spesifik pada substrat). Kedua, bisa dicampur dengan bermacam curing agents, pigmen dan binder lain untuk mendapatkan sifat-sifat khusus yang diinginkan. Epoxy dapat digunakan pada lapisan manapun dalam Coating System (Primer, Intermediate dan Top Coat).

\section{F. Aluminium}

Aluminium berasal dari biji aluminium alam yang dijumpai sebagai tambang bauksit yang mengandung kandungan utama aluminium oksida (alumina). Bauksit diolah dalam dapur listrik yang menghasilkan ingot aluminium. Aluminium tahan karat diudara karena membentuk paduan aluminium oksida hasil reaksi antara $\mathrm{O} 2$ diudara dengan permukaan logam aluminium. Lapisan aluminium ini berisi oksida yang cukup kedap udara dan tidak dapat terhembus dan ini menghambat terjadinya pengkaratan.

\section{G. Aluminium Sebagai Pigmen}

Aluminium sering digunakan dalam industri cat sebagai pigmen dalam bentuk powder ataupun pasta. Aluminium memiliki pigmen yang berbentuk platey atau lamellar Gambar 2 Bentuk pigmen tersebut sangat memengaruhi dalam peningkatan kualitas cat dengan cara meningkatkan barrier properties, dan ketahanan korosi, sehingga melindungi cat untuk terjadinya chalking dan cracking [3]

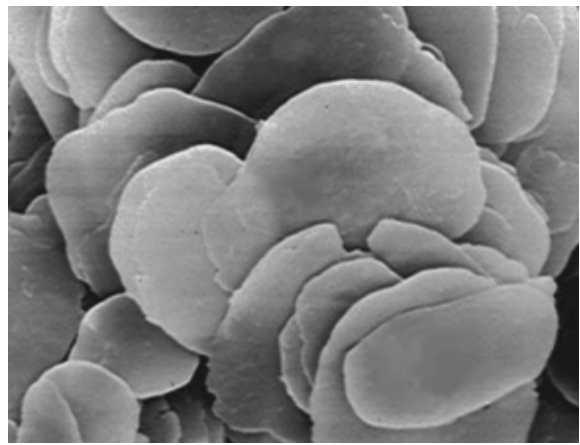

Gambar 2. Bentuk pigmen Aluminium.

Dalam pelapisan yang menggunakan aluminium sebagai pigmen akan terbentuk lapisan film alumina pada permukaan lapisan cat Gambar 3, sehingga dapat memberikan daya tahan lapisan cat terhadap berbagai bahan agresif.

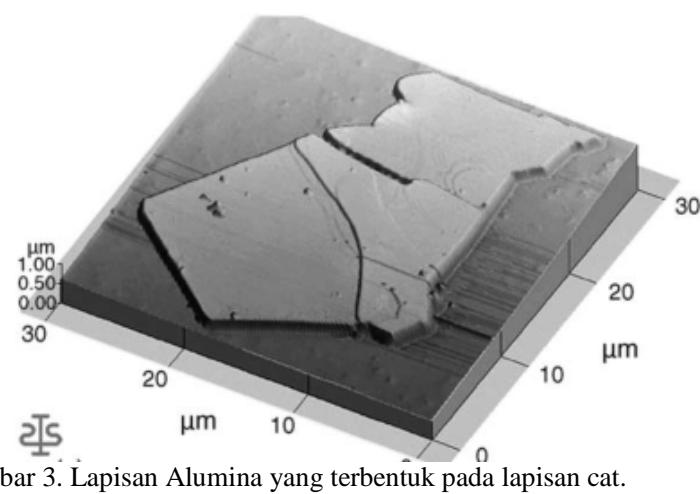

\section{METODOLOGI}

\section{A. Preparasi Spesimen}

1. Memotong logam menjadi ukuran 120 x 60 x $10 \mathrm{~mm}$ untuk digunakan sebagai spesimen pengujian adhesi sebanyak 9 buah.

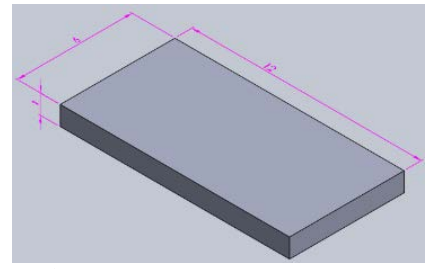

Gambar 4. Dimensi spesimen 12 x 6 x 1 cm. 
2. Memotong logam menjadi ukuran 40 x 20 x 10 mm untuk digunakan sebagai spesimen pengujian korosi sebanyak 8 buah.

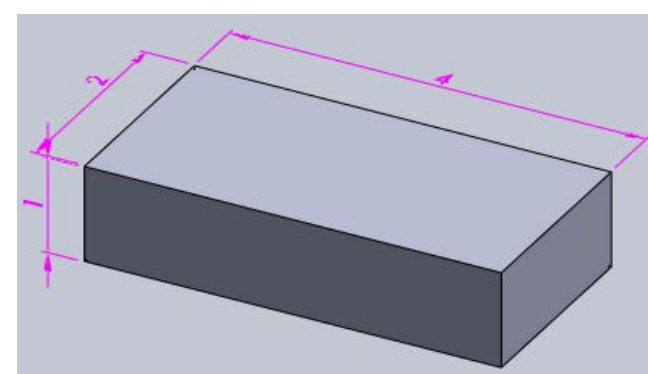

Gambar 5. Dimensi spesimen 4 × 2 x $1 \mathrm{~cm}$.

3. Memotong logam menjadi ukuran 10 x 10 x 10 mm untuk digunakan sebagai spesimen pengujian morfologi sebanyak 2 buah.

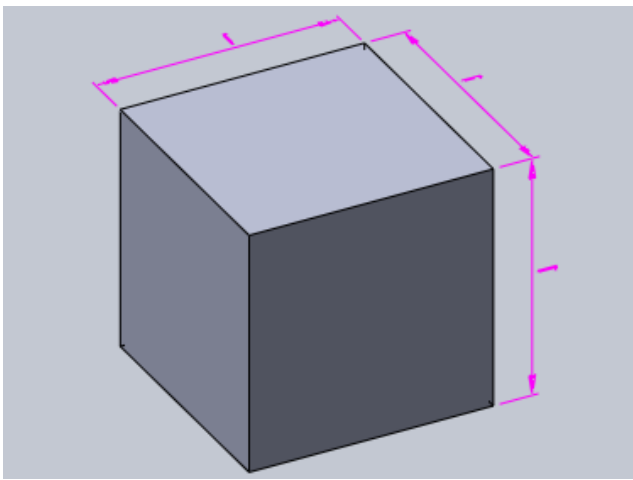

Gambar 6. Dimensi spesimen 1 x 1 x $1 \mathrm{~cm}$

\section{B. Proses Blasting}

Blasting merupakan salah satu proses yang sangat penting karena proses blasting dapat menentukan kualitas coating dari segi daya lekatnya. Tingkat keberhasilan penanggulangan korosi dengan menggunakan coating bergantung pada kebersihan dan kekasaran permukaan material sebelum diaplikasi coating. Tujuan utama dari blasting adalah membersihkan permukaan dari semua jenis kotoran. Tingkat kebersihan yang ingin dicapai dalam proses ini adalah SA 2 $1 / 2[4]$.

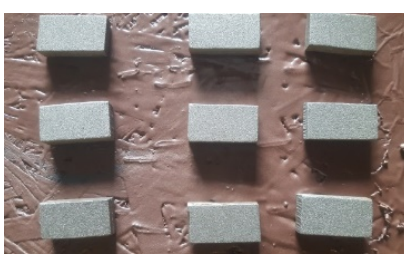

(a)

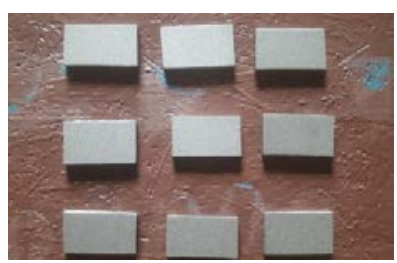

(b)
Gambar 7. Hasil spesimen yang telah diblasting (a) Spesimen uji prediksi laju korosi. (b) Spesimen uji kekuatan adhesi.

Setelah dilakukan proses blasting maka dilakukan pengukuran kekasaran permukandengan alat roughness meter. Tujuan dari pengukuran kekasaran permukaan adalah untuk mengetahui tingkat kekasaran blasting dari variasi sudut penyemprotan blasting yaitu $60^{\circ}, 75^{\circ}$, dan $90^{\circ}$.

Dari grafik dibawah dapat dilihat tren naik akibat dari variasi sudut penyemprotan blasting. Semakin besar sudut penyemprotan blasting maka nilai kekasaran permukaan semakin besar. Untuk nilai kekasaran tertinggi terdapat pada penyemprotan blasting pada sudut $90^{\circ}$ yaitu $123 \mu \mathrm{m}$.

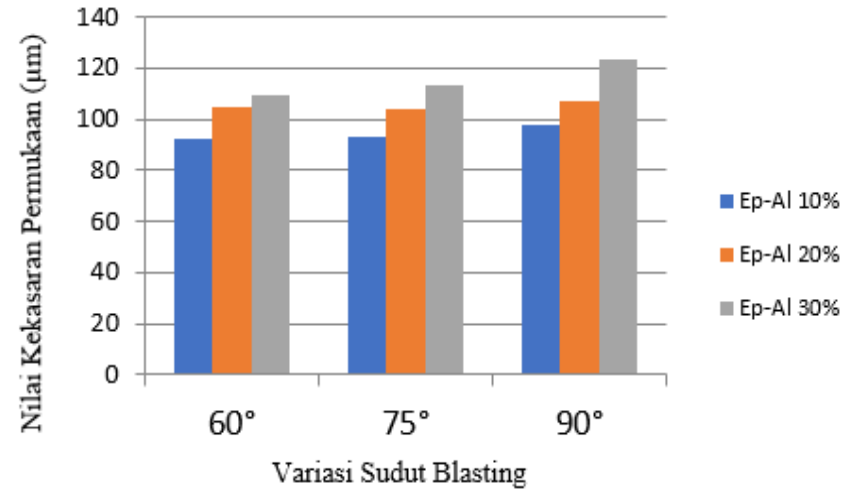

Gambar 8. Grafik nilai kekasaran permukaan

\section{Proses Coating}

Pada Studi ini coating yang digunakan menggunakan cat dengan bahan dasar epoxy primer yang di variasikan dengan penambahan aluminium serbuk. Variasi penambahan aluminium serbuk menggunakan variable 10\%, 20\% dan 30\% dari total volume keseluruhan $100 \% \mathrm{ml}$. Penulis juga menambahkan variasi sudut blasting dengan menggunakan sudut penyemprotan $60^{\circ}, 75^{\circ}, 90^{\circ}$.

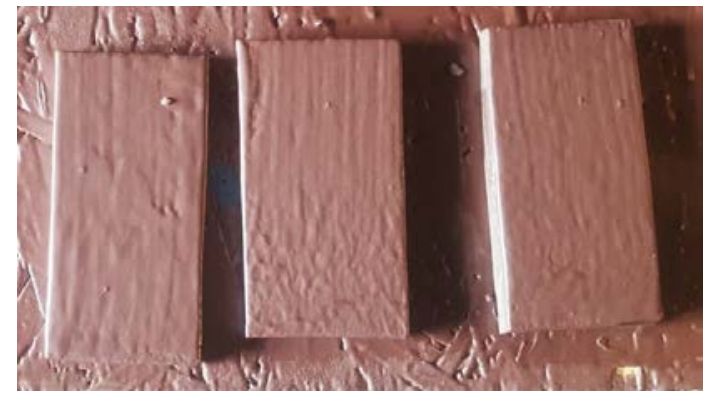

(a)

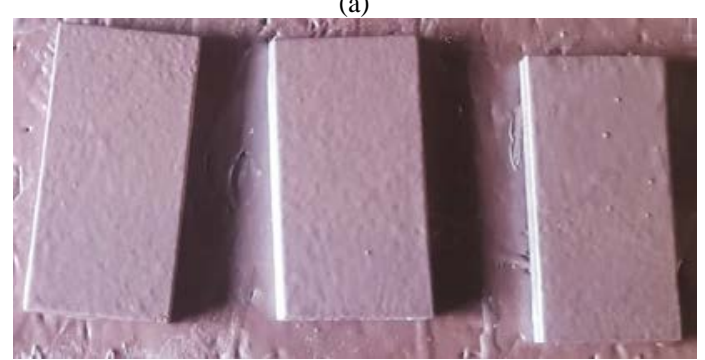

(b)

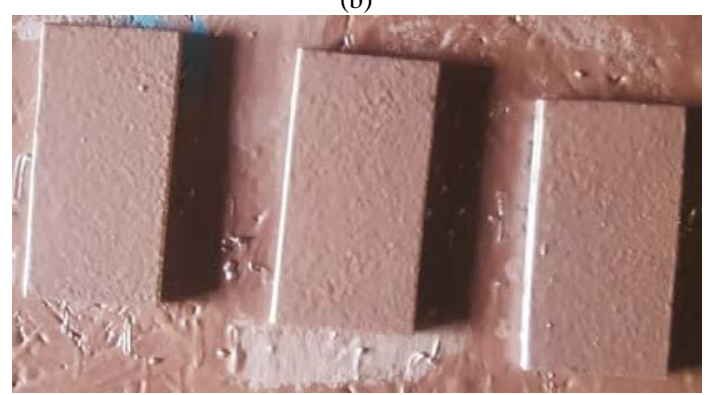

(c)

Gambar 9. Hasil coating (a) Campuran Ep-Al 10\%. (b) Campuran Ep-Al 20\%. (c) Campuran Ep-Al 30\%.

Aplikasi coating dilakukan dengan metode roll dengan asumsi setiap layer roll akan melapisi material $\pm 60 \mu \mathrm{m}$. Setiap pelpisan layer ditunggu kering sekitar 15 menit kemudian dilakukan hal yang sama sebanyak 4 layer. Setelah tahap aplikasi coating maka dilkukan pengukuran cat kering. 


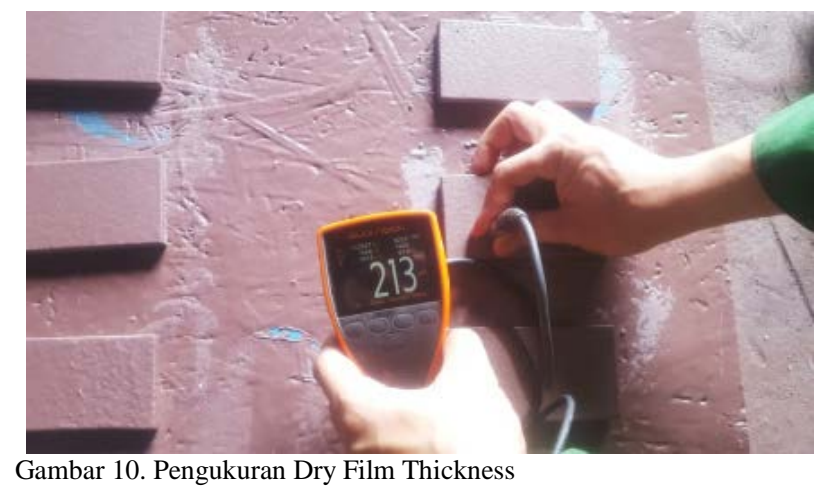

Pengukuran Dry Film Thickness dilakukan untuk mengetahui ketebalan cat epoxy yang telah diaplikasikan pada tiap-tiap spesimen. Hal ini diharapkan ketebalannya yaitu $250 \mu \mathrm{ml}$.

\section{HASIL ANALISA DAN PEMBAHASAN}

\section{A. Pengujian Kekuatan Adhesi}

Pengujian ini bertujuan untuk mengetahui pengaruh penambahan aluminium terhadap daya adhesi pada cat epoxy. Standard yang digunakan dalam pengujian ini adalah ASTM D4541 "Standard Test Method for Pull-Off Strength of Coatings Using Portable Adhesion testers". Metode yang digunakan dalam pengujian ini adalah metode pull off test. Metode ini menggunakan portable adhesion testers dan dolly sebagai alat bantu dalam pengujian. Berikut merupakan gambar hasil pengujian daya lekat coating dan nilai pengujian daya lekat coating pada spesimen plat baja ASTM A36 dengan penambahan aluminium dan variasi ketebalan coating:
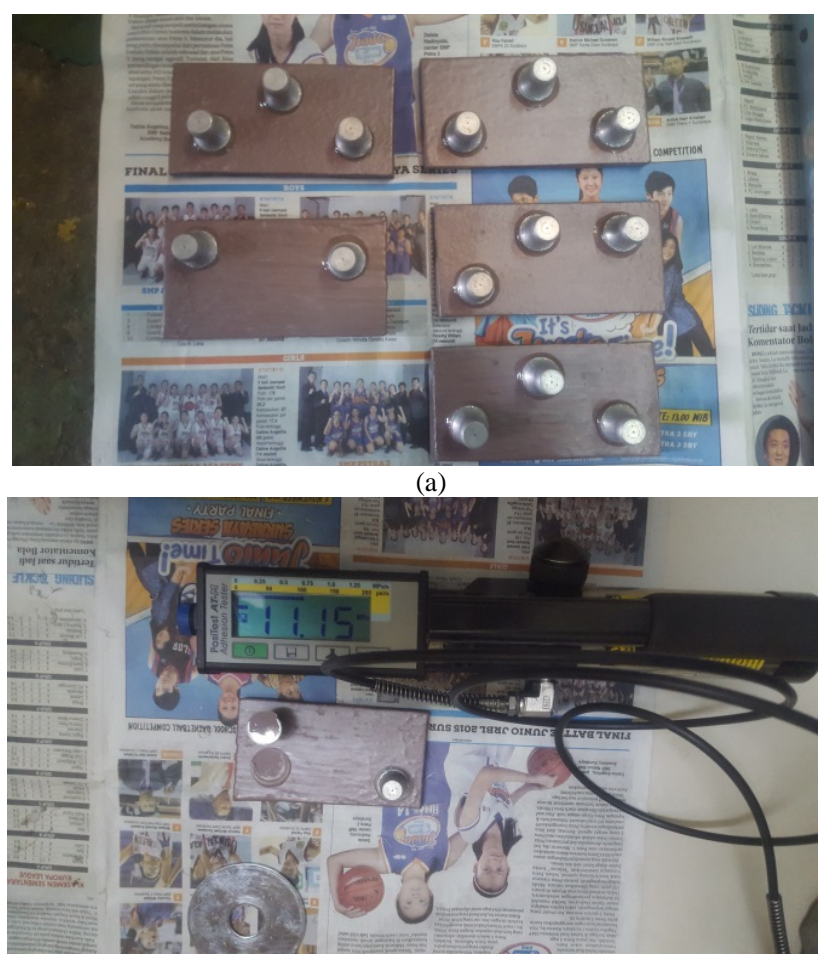

(b)

Gambar 11. (a) Dolly yang melekat pada spesimen, (b) Dolly terlepas dari spesimen akibat di pull off menggunakan alat portable adhesive tester.

Dari Gambar 8 dapat dilihat bahwa daya adhesi paling tinggi dimiliki oleh sampel dengan variasi sudut blasting $90^{\circ}$ dan penambahan aluminium serbuk $10 \%$ dengan nilai sebesar 14.9367 MPa. Sedangkan sampel dengan variasi sudut blasting $60^{\circ}$ dan penambahan aluminium 30\% memiliki daya adhesi paling kecil yaitu 10.1233 MPa.

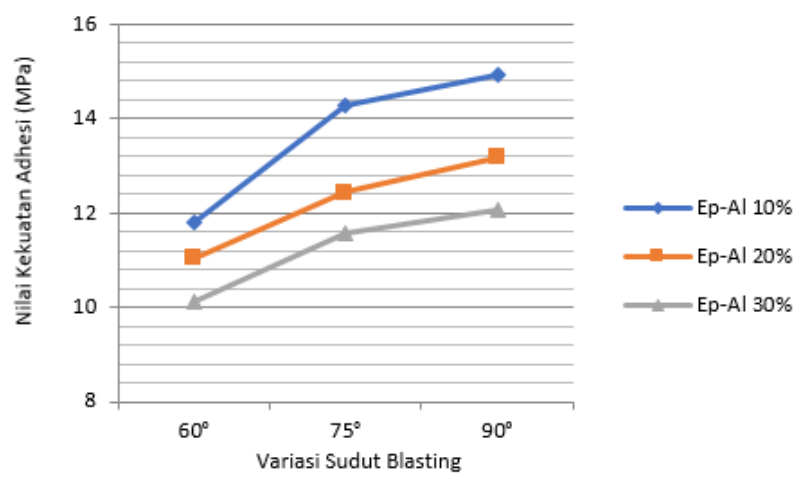

Gambar 12. Grafik nilai kekuatan adhesi.

Pada Gambar 12 didapat tren yang menunjukkan bahwa semakin sudut blasting dan semakin banyak aluminium serbuk yang ditambahkan pada epoxy, semakin kecil daya adhesi yang dimilikinya. Penurunan tersebut terjadi karena cohesive failure (ikatan cat-cat) bukan adhesive failure (ikatan cat-substrat) yang berarti adanya penurunan kekuatan ikatan diantara molekul-molekul yang terdapat dalam cat, dalam hal ini adalah epoxy-aluminium. Berikut merupakan hasil pengujian adhesive, cohesive dan glue pada saat pull-off test.

\section{B. Pengujian Prediksi Laju Korosi}

Pengujian ini bertujuan untuk mengetahui prediksi laju korosi dari setiap spesimen dengan variasi penambahan aluminium dan ketebalan coating. Metode yang digunakan ialah sel tiga elektroda yang berdasar pada ASTM G102 "Standard Practice for Calculation of Corrosion Rates and Related Information from Electrochemical Measurements" dengan dibantu oleh software CorrTest sebagai penerima respon terhadap potensial arus yang mengalir pada material yang telah dihubungkan dengan elektroda pembantu.

Data yang diperoleh dari pengujian korosi dengan metode sel tiga elektroda ini dilengkapi dengan grafik tafel. Grafik tafel ialah grafik yang menunjukkan potensial dan rapat arus yang digunakan pada uji korosi. Gambar 4.8 merupakan hasil grafik tafel yang didapatkan dari pengeplotan oleh software CorrTest.

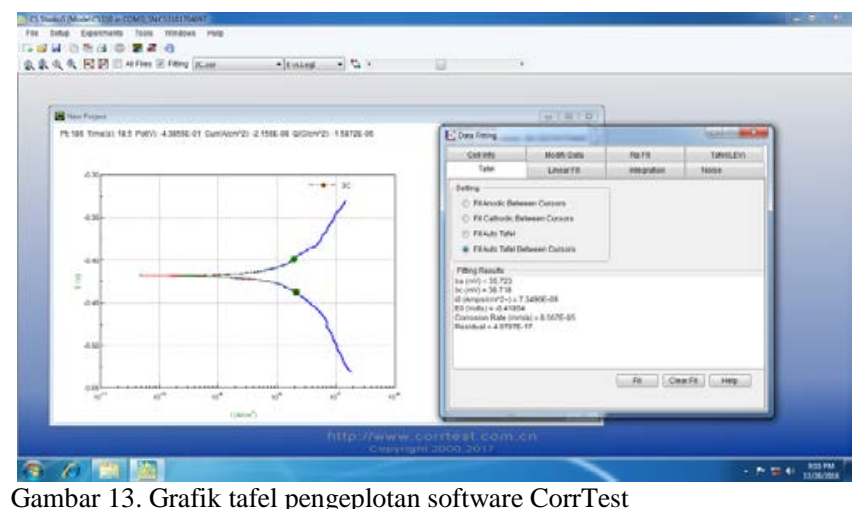

Pada grafik tabel ada dua sumbu, yaitu $\mathrm{Y}$ yang menunjukkan potensial (E corr), potensial pada pengujian sel tiga elektroda ini merupakan variable dependen. Sedangkan sumbu X menunjukkan rapat arus (I corr) yang dipakai, rapat arus dalam pengujian ini berubah-ubah sesuai dengan potensial yang dikenakan. Rapat arus dalam pengujian ini merupakan variable independen. Dari grafik tabel akan 
diperoleh titik-titik anoda dan katoda yang dapat membuat dua garis lurus. Perpotongan antara dua garis dari anoda dan katoda menunjukkan nilai rapat arus korosi.

Dari Gambar 10 dapat dilihat bahwa nilai laju korosi paling kecil dimiliki oleh sampel dengan variasi sudut blasting $90^{\circ}$ dan penambahan aluminium 30\% dengan nilai sebesar 0,00008567 mmpy. Sedangkan sampel dengan variasi sudut blasting $75^{\circ}$ dan penambahan aluminium serbuk $10 \%$ memiliki nilai laju korosi paling tinggi yaitu 0.0080706 mmpy.

Pada Gambar 14 grafik prediksi laju korosi didapat kesimpulan bahwa yang menunjukkan semakin besar sudut blasting pada material dan 30\% penambahan aluminium serbuk nilai laju korosi yang didapat semakin kecil. Sedangkan semakin kecil sudut blasting dan penambahan aluminium 10\% nilai laju korosi yang didapat semakin besar, karena aluminium memiliki kemampuan untuk bereksi dengan ion $\mathrm{OH}$. Hal ini mengakibatkan timbulnya aluminium hidrosida $\mathrm{Al}(\mathrm{OH}) 3$ pada permukaan baja yang menyebabkan peningkatan ketahanan terhadap korosi.

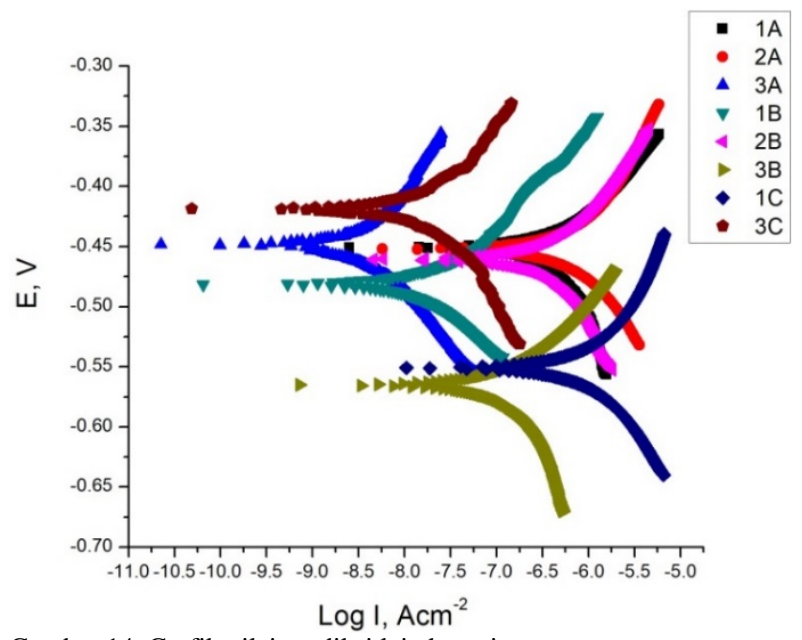

Gambar 14. Grafik nilai prediksi laju korosi

\section{Sifat Morfologi}

Pada tahap ini dilakukan foto mikro dengan menggunkan mikroskop optik dan mikroskop metalurgi. Dalam pengambilan sampel foto dilakukan dengan beberapa ukuram pembesaran. Dalam tahap ini digunakan untuk mengethui struktur mikro pada pencampuran cat epoxy dan aluminium serbuk dan persebaran aluminium serbuk pada material yang sudah di coating.

Foto mikro menggunakan mikroskop optik dengan spesimen uji coating ukuran $10 \mathrm{~mm}$ x $10 \mathrm{~mm}$ menyesuaikan dengan kapasitas muat mikroskop optik. Foto mikro lapisan dari spesimen uji ditampilkan pada Gambar. Foto mikro terlihat terdiri dari dua bagian, dimana bagian atas adalah lapisan coating Epoxy Jotun Jotacote Uni Alu RT A dan bagian bawah adalah substrat baja ASTM A36 dengan kekasaran permukaan tertentu. Tampak bahwa lapisan coating epoxy memiliki ketebalan yang berbeda sesuai bentuk profil permukaan.

Dari pengamatan cross section pada mikroskop optik pada pengujian SEM dapat dilihat bahwa terdapat persebaran butir-butir aluminium pada lapisan cat epoxy. Pada perbesarn 4000x terlihat jelas butir-butir almunium yang menyebar diseluruh permukaan lapisan. Pada pengamatan cross section terjadi mechanical bonding antara substrate dan epoxy, ikatan tersebut terjadi karena adanya kekasaran permukaan pada baja yang telah dilakukan proses blasting kemudian diisi oleh epoxy kemudian terjadi pengerasan. Semakin kasar suatu permukaan material maka mechanical bonding akan semakin kuat ditambah dengan penambahan aluminium maka celahcelah yang tidak sempat tertutup oleh substrate pada epoxy akan diisi dengan aluminium. Hal ini juga akan meningkatkan terhadap coating disbondment yng lebih efektif. Pada pengamatan cross section sendiri terlihat pigmen aluminium yang berbentuk platey atau lamellar. Bentuk pigmen tersebut sangat memengaruhi dalam peningkatan kualitas cat dengan cara meningkatkan barrier properties, dan ketahanan korosi, sehingga melindungi cat untuk terjadinya chalking dan cracking.

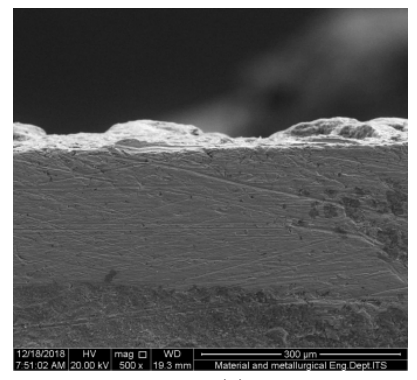

(a)

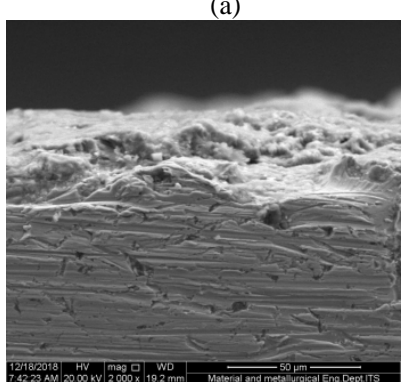

(c)

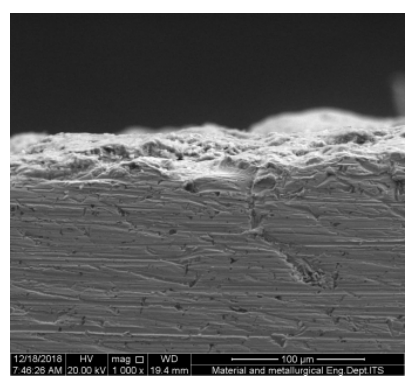

(b)

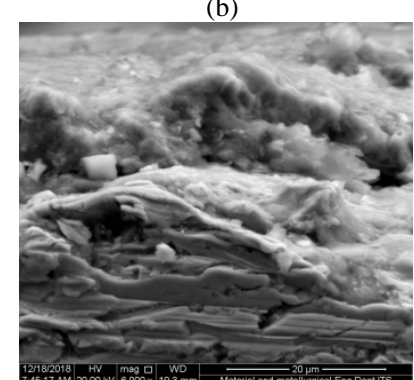

(d)
Gambar 15. Pengamatan pada pengujian SEM (a) 500x (b) 1000x (c) 2000x (d) $6000 \mathrm{x}$.

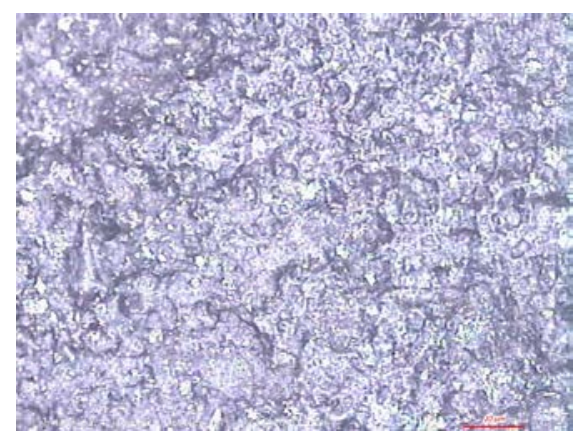

Gambar 16. Hasil pengamatan dengan mikroskop metalurgi perbesaran 100x.

Dari pengamatan mikroskop metalurgi dapat dilihat bahwa perbedaan warna yang dapat dilihat melalui pengamatan visual terjadi karena persebaran aluminium serbuk dipermukaan sampel yang merata, sehingga semakin banyak penambahan aluminium yang ditambahkan semakin cerah warna yang didapatkan coating tersebut. Penambahan aluminium serbuk memberikan paket-paket aluminium pada cat epoxy hal ini berguna sebagai sacrificial anode dan sebagai prevent terhadap coating disbondment dimana aluminium mengisi ikatan-ikatan antara epoxy-epoxy yang akan membentuk poros yang lebih efektif pada lapisan epoxy.

\section{KESIMPULAN}

Dari pengujian adhesi menggunakan metode pull of test didapatkan nilai kekuatan adhesi paling tinggi dimiliki oleh spesimen dengan penambahan aluminium 10\% dan variasi 
sudut blasting $90^{\circ}$ dengan nilai sebesar $14.9367 \mathrm{MPa}$, sedangkan untuk spesimen dengan penambahan aluminium $30 \%$ dan variasi sudut blasting $60^{\circ}$ memiliki nilai kekuatan adhesi sebesar 10.1233 MPa. Seiring dengan penambahan aluminium pada cat epoxy menyebabkan turunnya nilai kekuatan adhesi pada material.

Pada pengujian laju korosi dengan metode sel tiga elektroda, didapatkan nilai laju korosi paling kecil terdapat di spesimen dengan penambahan aluminium 30\% dan variasi sudut blasting $90^{\circ}$ dengan nilai laju korosi 0,00008567 mmpy, sedangkan untuk spesimen dengan penambahan aluminium $10 \%$ dan variasi sudut blasting $75^{\circ}$ memilliki nilai laju korosi paling tinggi yaitu 0.0080706 mmpy. Sehingga, semakin banyak penambahan aluminium maka semakin baik ketahanan korosi coating tersebut dan semakin rendah nilai laju korosinya.

Dari hasil pengamatan cross section pada mikroskop optik pada pengujian SEM dapat dilihat bahwa terdapat persebaran butir-butir aluminium pada lapisan cat epoxy dan terlihat pigmen aluminium yang berbentuk platey atau lamellar. Bentuk pigmen tersebut sangat memengaruhi dalam peningkatan kualitas cat dengan cara meningkatkan barrier properties, dan ketahanan korosi. Dari pengamatan mikroskop metalurgi dapat dilihat bahwa perbedaan warna yang dapat dilihat melalui pengamatan visual terjadi karena persebaran aluminium serbuk dipermukaan sampel yang merata. Penambahan aluminium serbuk memberikan paketpaket aluminium pada cat epoxy hal ini berguna sebagai sacrificial anode dan sebagai prevent terhadap coating disbondment

\section{DAFTAR PUSTAKA}

[1] W. Rianiri, Akbar dan Hendroprasetyo, “Analisis pengaruh ketebalan nonconductive coating terhadap kemampuan pendeteksian panjang dan kedalamanretak pada fillet joint bracket kapalaluminium menggunakan pengujian ultrasonik,” J. Tek. Pomits, vol. 2, no. 1, 2013

[2] J. . Keijiman, "Achieving quality in coating work: the 21st century challenge,” in Proceeding Inorganic and Organic Coating - The Difference, 1999.

[3] ASCOATINDO, “Coating inspector muda,” Bandung, 2014.

[4] I. 8501, "Corrosion protection of steel structures by painting," 2011. 